\title{
Magnetic resonance imaging features of vascular leiomyoma of the ankle
}

\author{
Alta YT Lai *, CW Tam, John SF Shum, Jennifer LS Khoo, WL Tang
}

\begin{abstract}
A B S T R A C T
Vascular leiomyoma is a benign soft tissue tumour with a predilection for middle-aged women. It is most often seen in the extremities, particularly in the lower leg. The typical lesion is a small, slow-growing subcutaneous nodule. These tumours are often unexpected or preoperatively confused with other soft tissue tumours including low-grade sarcomas, leading to wide surgical excision. This may partly be due to the relatively few studies delineating the characteristic imaging features of this entity. Here, the imaging findings of a case of vascular leiomyoma in the ankle are presented. Literature review of the magnetic resonance imaging findings of published reports and series of vascular leiomyomas of the extremities is also performed.
\end{abstract}

Hong Kong Med J 2015;21:73-6 DOI: 10.12809/hkmj144259

${ }^{1}$ AYT Lai *, MB, BS, FRCR

CW Tam, FRCR, FHKAM (Radiology)

2 JSF Shum, FRCR, FHKAM (Radiology)

1 JLS Khoo, FRCR, FHKAM (Radiology)

${ }^{3}$ WL Tang, FHKCPath, FHKAM (Pathology)

${ }^{1}$ Department of Radiology, Pamela Youde Nethersole Eastern Hospital, Chai Wan, Hong Kong

2 Radiology Department, Hong Kong Baptist Hospital, Kowloon Tong, Hong Kong

3 Department of Clinical Pathology, Pamela Youde Nethersole Eastern Hospital, Chai Wan, Hong Kong

* Corresponding author: altalai@gmail.com

\section{Case report}

A 47-year-old previously healthy Hong Kong Chinese man presented in January 2012 with a 2 -year history of a slow-growing painless mass over the right medial malleolus. Physical examination showed a soft, well-marginated, non-tender mass measuring $2 \mathrm{~cm}$ in diameter over the right medial malleolus. The patient was referred for ultrasound and subsequently magnetic resonance imaging (MRI; Figs a to i). The lesion was excised. Macroscopically, it was a disc-shaped mass with smooth outer surface. Cut section showed a mass with a thin capsule and homogeneous, greyish-to-whitish material without necrosis. Microscopy showed proliferation of smooth muscle cells associated with thick-walled blood vessels without evidence of malignancy. The histopathological diagnosis was vascular leiomyoma (Figs $\mathrm{j}$ and $\mathrm{k}$ ).

\section{Discussion}

Vascular leiomyoma, angiomyoma or angioleiomyoma, is a rare benign smooth muscle tumour that originates in the tunica media of veins and arteries. It can be located in the skin, subcutaneous fat, or superficial fasciae of the extremities. It has a predilection for middle-aged women. It can occur anywhere in the body, but is most often seen in the extremities, particularly in the lower leg. ${ }^{1}$

The most frequent clinical presentation is a mass that enlarges slowly over several years. The size usually ranges from subcentimetre to a few centimetres in diameter, but occasionally may grow larger. They are usually oval or round in shape, and can be located in the skin, subcutaneous fat, or the superficial fasciae of the extremities.

Pain, with or without tenderness, has been reported in about $60 \%$ of patients, and is thought to be caused by the active contraction of smooth muscles resulting in local ischaemia, and is also suggested to be mediated by intratumoural nerve fibres. ${ }^{2}$ Treatment usually consists of marginal excision. ${ }^{2}$

Angioleiomyomas are rarely diagnosed preoperatively. In a series of 10 cases by Gupte et $\mathrm{al}^{1}$ in 2008, the preoperative or pre-biopsy imaging diagnoses included sarcoma not otherwise specified, schwannoma, myositis ossificans, synovial sarcoma, and fibroma. This may be partly due to the relatively few studies delineating the characteristic imaging features of this entity. The preoperative differentiation of angioleiomyoma from other soft tissue tumours is of clinical importance, especially sarcomas, since angioleiomyomas are benign and can be treated with simple excision. Literature review of the MRI findings of currently published reports and series of vascular leiomyomas of the extremities is presented below.

\section{Literature review}

Materials, methods, and patient demographics

A PubMed search of the English literature 


\section{腳踝血管性平滑肌瘤的磁力共振影像特徵}

黎爾德、譚枝慧、岑承輝、邱麗珊、鄧偉倫

血管性平滑肌瘤是一種良性軟組織瘤, 患者多為中年女性, 通常見於 四肢, 尤其下肢。典型的血管性平滑肌瘤是一顆生長緩慢的小結節。

手術之前一般很難預料到這種瘤, 也容易和其他軟組織瘤混淆, 例如 一些低度惡性肌瘤, 因而引致廣泛切除的手術方法。部分原因可能是 現時文獻有較少關於血管性平滑肌瘤特有的影像診斷特色。本文報告 一宗位於腳踝的血管性平滑肌瘤的病例, 並回顧相關文獻。 was performed, using the key words "vascular leiomyoma", "angioleiomyoma”, and "angiomyoma". From 1998 to 2011, 36 cases of biopsy-proven vascular leiomyomas in the extremities of adults with detailed descriptions of $\mathrm{T} 1$-weighted images (T1WI) and T2-weighted images (T2WI) were found. Articles without detailed descriptions or figures of T1WI and T2WI were excluded. Not all studies in the literature may have been included in this review because of unavailability in PubMed or in English language. After including our case, this review has 37 cases. The mean age of the patients

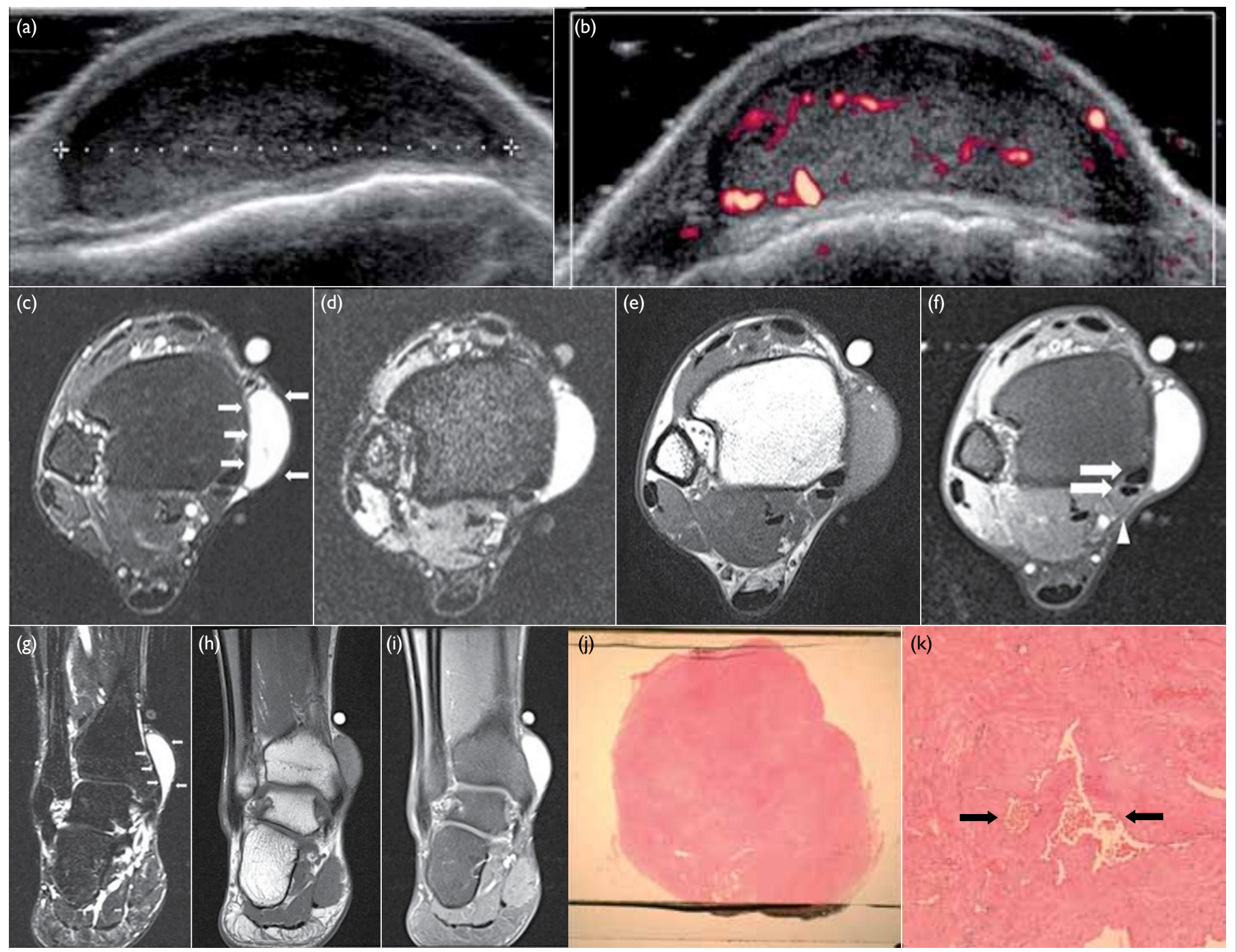

FIG. A 47-year-old man with a 2-year history of a slow-growing, painless, soft ankle mass

(a) Grey-scale ultrasound and (b) power Doppler study demonstrate a well-circumscribed, mildly compressible, mildly echogenic, subcutaneous lesion adjacent to the right medial malleolus with intralesional slow-flow vessels. No feeding artery, dilated draining vein, or phlebolith is found. Overall features are suggestive of a mildly vascular solid mass. $(c, g)$ It is well-circumscribed and markedly hyperintense with a peripheral hypointense rim (arrows) on axial and coronal T2-weighted images. (d) No susceptibility artefacts are observed in the lesion on gradient echo sequence image, suggesting the absence of intralesional haemorrhage. $(e, h)$ It is slightly hyperintense to muscle on $\mathrm{TI}$-weighted images, with ( $\mathrm{f}, \mathrm{i})$ homogeneous enhancement upon intravenous administration of gadolinium. The underlying bone, subjacent flexor retinaculum (arrowhead) and medial ankle tendons (arrows) were intact. (j, k) Microscopic pictures of the tumour section include central blood vessels (arrows) surrounded by peripheral smooth muscle. The histopathological diagnosis is vascular leiomyoma $(H \& E$, original magnification: $[j] \times 5$ and $[\mathrm{k}] \times 100)$ 
was 51 years (range, 20-72 years). There were 16 male and 17 female patients; the gender of the remaining four patients was not stated.

\section{Results}

Among the 26 lesions with documented sizes, the mean size of the lesions was $3.2 \mathrm{~cm}$ (range, 0.4-12 $\mathrm{cm})$. Overall, $40.5 \%(15 / 37)$ of the lesions were in the upper limb and $59.5 \%(22 / 37)$ were in the lower limb. All of them were located in the subcutaneous layer, were well-defined, and round, oval or disc-shaped. On T1WI, 91.9\% (34/37) of the tumours showed isointense-to-slightly high signal intensity, 5.4\% were heterogeneous, and $2.7 \%$ showed low signal intensity. On T2WI, all the cases demonstrated high signal intensity. Signal voids were seen in $10.8 \%(4 / 37)$ of the tumours, either on T1WI or T2WI. Among the 33 cases in which contrast was administered, only two $(6.1 \%)$ cases showed no or poor enhancement, 93.9\% (31/33) showed enhancement, 42.4\% (14/33) were homogeneous, and $39.4 \% \quad(13 / 33)$ were described as showing heterogeneous enhancement. One case showed peripheral enhancement, one showed central enhancement. One case showed rapid enhancement and one case demonstrated slow enhancement. Among the cases in which the presence or absence of peripheral hypointense rim was recorded, a hypointense rim was found on T2WI in $85.2 \%$ of cases $\left(23 / 27\right.$; Table $\left.{ }^{1-14}\right)$.

Vascular leiomyomas often show similar signal intensity to that of muscle on T1WI. A T2WI is expected to demonstrate mixed areas that are hyperand isointense to muscle. A well-defined peripheral T2-hypointense rim may be seen, representing the fibrous capsule. It has been reported that $\mathrm{T} 2$ hyperintense areas correlated with strong contrast enhancement, whereas isointense areas did not show enhancement after intravenous administration of contrast material. ${ }^{3}$ It was suggested that the smooth muscle and numerous vessels corresponded to the hyperintense areas, and the fibrous tissue appeared isointense on T2WI. Tortuous vascular structures with signal void may also be seen.

\section{Imaging differentials}

The differentials of a well-defined, enhancing, subcutaneous nodule or mass with T2-hyperintense signals include synovial sarcoma, other low-grade soft tissue sarcomas, haemangioma, neurogenic tumour, and nodular fasciitis.

Low-grade sarcomas such as synovial sarcoma and low-grade myxofibrosarcoma may be slow growing and appear well-circumscribed on MRI, giving the misleading impression that the lesion is well-localised. Haemorrhage may be present in synovial sarcomas, which may be seen as fluid-fluid levels, T2 hypointensity, or "triple signal intensity", namely areas of hyperintensity, isointensity and
TABLE. Magnetic resonance imaging findings in 37 patients with vascular leiomyomas in extremities ${ }^{1-14}$

\begin{tabular}{|c|c|}
\hline Variable & Data \\
\hline \multicolumn{2}{|l|}{ Age in years (among 33 patients with documented age) } \\
\hline Mean & 51 \\
\hline Range & $20-72$ \\
\hline \multicolumn{2}{|l|}{ Sex (among 33 patients with documented sex) } \\
\hline Male & $16(48.5 \%)$ \\
\hline Female & $17(51.5 \%)$ \\
\hline \multicolumn{2}{|l|}{ Location $(n=37)$} \\
\hline Upper limb & $15(40.5 \%)$ \\
\hline Lower limb & $22(59.5 \%)$ \\
\hline \multicolumn{2}{|l|}{ Size in cm (among 26 lesions with documented sizes) } \\
\hline Mean & 3.2 \\
\hline Range & $0.4-12$ \\
\hline \multicolumn{2}{|l|}{ Shape } \\
\hline Well-defined; and were round, oval or disc-shaped & All \\
\hline \multicolumn{2}{|l|}{ T1-weighted signal intensity to muscle $(n=37)$} \\
\hline Isointense-to-slightly high signal intensity & $34(91.9 \%)$ \\
\hline Heterogeneous & $2(5.4 \%)$ \\
\hline Slightly low & $1(2.7 \%)$ \\
\hline \multicolumn{2}{|l|}{ T2-weighted signal intensity to muscle } \\
\hline High signal intensity & $100 \%$ \\
\hline Signal void on either T1- or T2-weighted images $(n=37)$ & $4(10.8 \%)$ \\
\hline \multicolumn{2}{|l|}{ Enhancement $(\mathrm{n}=33)$} \\
\hline No or poor enhancement & $2(6.1 \%)$ \\
\hline Enhancement present & $31(93.9 \%)$ \\
\hline Homogeneous enhancement & $14(42.4 \%)$ \\
\hline Heterogeneous enhancement & $13(39.4 \%)$ \\
\hline Rapid enhancement & $1(3.0 \%)$ \\
\hline Slow enhancement & $1(3.0 \%)$ \\
\hline Enhancing, not otherwise specified & $2(6.1 \%)$ \\
\hline \multicolumn{2}{|l|}{$\begin{array}{l}\text { Peripheral T2-hypointense rim (among cases where its } \\
\text { presence/absence was noted) [ } n=27]\end{array}$} \\
\hline Hypointense rim present & $23(85.2 \%)$ \\
\hline
\end{tabular}

hypointensity relative to fat, due to presence of cystic, solid and fibrous elements with haemorrhage. It is unknown whether the absence of haemorrhage, a more homogeneous appearance, and the presence of a peripheral hypointense rim are reliable distinguishing features favouring angioleiomyoma over otherwise benign-appearing, soft tissue sarcomas; this may be a potential knowledge gap that future prospective comparison studies may serve to fill.

Haemangiomas may show homogeneous signals if these are small, making it challenging to differentiate from angioleiomyomas. Phleboliths 
can be sought for on plain radiographs. Fatty and serpentine vascular elements may be identified in haemangiomas, which are pathognomonic. The classical 'target' sign, 'split-fat' sign, and fusiform tumour shape demonstrated in neurogenic tumours are not found in angioleiomyomas. Although nodular fasciitis demonstrates similar shape and size as angioleiomyomas, linear extension along the fascia, surrounding oedema, low T1 signal, heterogeneous T2 signal, and non-homogeneous enhancement are features that differ from characteristic imaging features of angioleiomyoma. ${ }^{15}$

On microscopic examination, the presence of tortuous vascular channels surrounded by smooth muscle bundles and areas of myxoid change may be seen. This explains the heterogeneity of signal intensity in the tumour on T2WI. Magnetic resonance imaging-histopathological correlation published by Hwang et $\mathrm{al}^{2}$ stated that the smooth muscle and numerous vessels within each type of vascular leiomyoma corresponded with the hyperintense areas on T2WI, and the tough fibrous tissue appeared isointense on T2WI. In addition, a well-defined peripheral hypointense area on T2WI correlated with the fibrous capsule, and the interlacing isointense areas within the tumour correlated with the various quantity of connective tissue and intravascular thrombus. ${ }^{3}$

\section{Conclusions}

Vascular leiomyoma should be considered a possible diagnosis when a well-demarcated oval or round subcutaneous mass with T1-isointense-to-slightly high signal, T2-high signal intensity, hypointense rim, and intense enhancement is seen in the soft tissue of the extremities. It is unknown whether the absence of haemorrhage, a more homogeneous appearance, and the presence of a peripheral hypointense rim are reliable distinguishing features favouring angioleiomyoma over otherwise benignappearing soft tissue sarcomas; this may be a potential knowledge gap that future prospective comparison studies may serve to fill.

\section{References}

1. Gupte C, Butt SH, Tirabosco R, Saifuddin A. Angioleiomyoma: magnetic resonance imaging features in ten cases. Skeletal Radiol 2008;37:1003-9.

2. Hwang JW, Ahn JM, Kang HS, Suh JS, Kim SM, Seo JW. Vascular leiomyoma of an extremity: MR imagingpathology correlation. AJR Am J Roentgenol 1998;171:9815.

3. Yoo HJ, Choi JA, Chung JH, et al. Angioleiomyoma in soft tissue of extremities: MRI findings. AJR Am J Roentgenol 2009;192:W291-4.

4. Kinoshita T, Ishii K, Abe Y, Naganuma H. Angiomyoma of the lower extremity: MR findings. Skeletal Radiol 1997;26:443-5.

5. Turhan-Haktanir N, Haktanir A, Demir Y, Tokyol C, Acar M. Toe leiomyoma: A case report with radiological correlation. Acta Chir Belg 2006;106:92-5.

6. Nagata S, Nishimura H, Uchida M, Hayabuchi N, Zenmyou M, Fukahori S. Giant angioleiomyoma in extremity: report of two cases. Magn Reson Med Sci 2006;5:113-8.

7. Hamoui M, Largey A, Ali M, et al. Angioleiomyoma in the ankle mimicking tarsal tunnel syndrome: a case report and review of the literature. J Foot Ankle Surg 2010;49:398. e9-15.

8. Shafi M, Hattori Y, Doi K. Angioleiomyoma of distal ulnar artery of the hand. Hand (N Y) 2010;5:82-5.

9. Gulati MS, Kapoor A, Maheshwari J. Angiomyoma of the knee joint: value of magnetic resonance imaging. Australas Radiol 1999;43:353-4.

10. Kugimoto Y, Asami A, Shigematsu M, Hotokebuchi T. Giant vascular leiomyoma with extensive calcification in the forearm. J Orthop Sci 2004;9:310-3.

11. Waldt S, Rechl H, Rummeny EJ, Woertler K. Imaging of benign and malignant soft tissue masses of the foot. Eur Radiol 2003;13:1125-36.

12. Sookur PA, Saifuddin A. Indeterminate soft-tissue tumors of the hand and wrist: a review based on a clinical series of 39 cases. Skeletal Radiol 2011;40:977-89.

13. Okahashi K, Sugimoto K, Iwai M, Oshima M, Takakura Y. Intra-articular angioleiomyoma of the knee: a case report. Knee 2006;13:330-2.

14. Stock H, Perino G, Athanasian E, Adler R. Leiomyoma of the foot: sonographic features with pathologic correlation. HSS J 2011;7:94-8.

15. Walker EA, Fenton ME, Salesky JS, Murphey MD. Magnetic resonance imaging of benign soft tissue neoplasms in adults. Radiol Clin North Am 2011;49:1197-217. 